\title{
산개성단 M48(NGC 2548) 영역의 새로운 변광성 NEW VARIABLE STARS IN THE REGION OF THE OPEN CLUSTER M48 (NGC 2548)
}

\author{
전영범, 이혜란 \\ 한국천문연구원 \\ Young-Beom JeOn AND Hye-RAn LeE \\ Korea Astronomy and Space Science Institute \\ E-mail: ybjeon@kasi.re.kr \\ (Received November 7, 2011; Accepted November 21, 2011)
}

\begin{abstract}
In the region of the open cluster M48 (NGC 2548), time-series BV CCD images were taken for 22 nights from February 28 in 2008 to March 17 in 2011. From this observation, we found 10 new variable stars. They include five eclipsing binaries, an RR Lyrae, two $\delta$ Scuti, and two semi-periodic and/or slow irregular type variable stars. We fail to find the member stars of the open cluster among the 10 variable stars.
\end{abstract}

Key words: clusters: M48 (NGC 2548); stars: variables: RR Lyrae, $\delta$ Scuti, eclipsing binaries; wide-field photometry

\section{1. 서론}

단주기 변광성 탐사 프로그램인 SPVS(Short-Period Variability Survey; Jeon et al., 2005, 2007)의 일환으 로 그동안 M50(Jeon, 2008), M38(Jeon, 2009a, 2010a), M29(Jeon, 2009b), M35(Jeon \& Lee, 2010b) 등의 영역 에 대한 변광성 탐사 연구를 수행하였다.

산개성단 $\mathrm{M} 48$ (NGC 2548)은 은하 중심 반대 방향 $(l$ $\left.=227.873^{\circ}, b=15.393^{\circ}\right)$ 에 위치하며, 좌표 $(\mathrm{J} 2000.0)$ 는 적경 $\alpha=8^{h} \quad 13^{m} \quad 43^{s}$, 적위 $\delta=-05^{\circ} \quad 45^{\prime}$ 이 다. 이 성단의 거리는 $769 \mathrm{pc}$, 성간소광량은 $E(B-$ $V)=0.03$, 나이는 약 4 억년으로서 중간나이 산개성단 이다(WEBDA $\left.{ }^{1}\right) \cdot \operatorname{Pesch}(1961)$ 는 Ebbighausen(1939)의 고유운동 연구로부터 성단의 구성원으로 알려진 37 개 별에 대해 $U B V$ 의 광전등급을 구하여 성간소광량을 얻 었는데 그 값은 $E(B-V)=0.04$ 으로서 $\mathrm{WEBDA}$ 의 값 과 비슷하다. 이 성단의 시직경은 약 $30^{\prime}(\mathrm{WEBDA})$ 으 로서 $155 \mathrm{~mm}$ 소형망원경으로 관측하기에 적당한 대 상이다. 그동안 M48 영역에 대해서는 고유운동 연 구(Ebbighausen, 1939; Wu et al., 2002, 2006)와 측광 연구(Pesch, 1961; Balaguer-Núñez et al., 2005; Rider et al., 2004; Sharma et al., 2006) 등은 비교적 많이 이 루어졌지만 변광성 탐사는 이루어진 예가 없다.

\footnotetext{
${ }^{1}$ http://www.univie.ac.at/webda/
}

2 절에서는 관측 및 분석을 정리하고, 3 절에 그 결과 를, 그리고 마지막 절에 전체 결과의 요약과 검토에 대 해 기술한다.

\section{2. 관측 및 분석}

이 연구에 사용한 관측 장비는 보현산천문대의 $155 \mathrm{~mm}$ 굴절망원경과 $\mathrm{AP} 9 \mathrm{E}$ (전기냉각방식, $2 \mathrm{k} \times 3 \mathrm{k}$; Apogee 사) $\mathrm{CCD}$ 카메라이며, $1.0^{\circ} \times 1.5^{\circ}$ 의 넓은 영역을 포 함한다. 따라서 M48 영역을 충분히 넓게 포함한 변광 성 탐사가 가능하다. 관측 장비에 대한 자세한 내용은 Jeon et al. $(2005,2007)$ 를 참고하면 된다.

연구에 이용한 자료는 2008 년 2 월 28 일부터 3 월 20 일 사이에 8 일간, 2011 년 2 월 22 일부터 3 월 17 일 사이에 14 일간 관측하여 총 22 일 관측한 것이다. 총 관측 시 간은 약 76 시간이다. 사용한 필터는 $B$ 와 $V$ 이며, 노출 시간은 모두 150 초이다. 약 640 여회의 관측 중에서 날 씨 등으로 인해 측광오차가 크고, 광도곡선 상에서 분 산이 큰 자료를 제외하였다. 따라서 실제 연구에 사용 한 자료는 가장 어두운 변광성의 경우 $B$ 필터와 $V$ 필 터에 대해 각각 354 개와 545 개였고, 가장 밝은 변광성 의 경우 각각 607 개와 603 개였으며, 대부분 580 개 안팎 의 관측 자료를 사용하였다. $B$ 와 $V$ 각각에 대해 10 초 와 5 초의 짧은 노출을 사용하여 밝은 별에 대한 짧은 


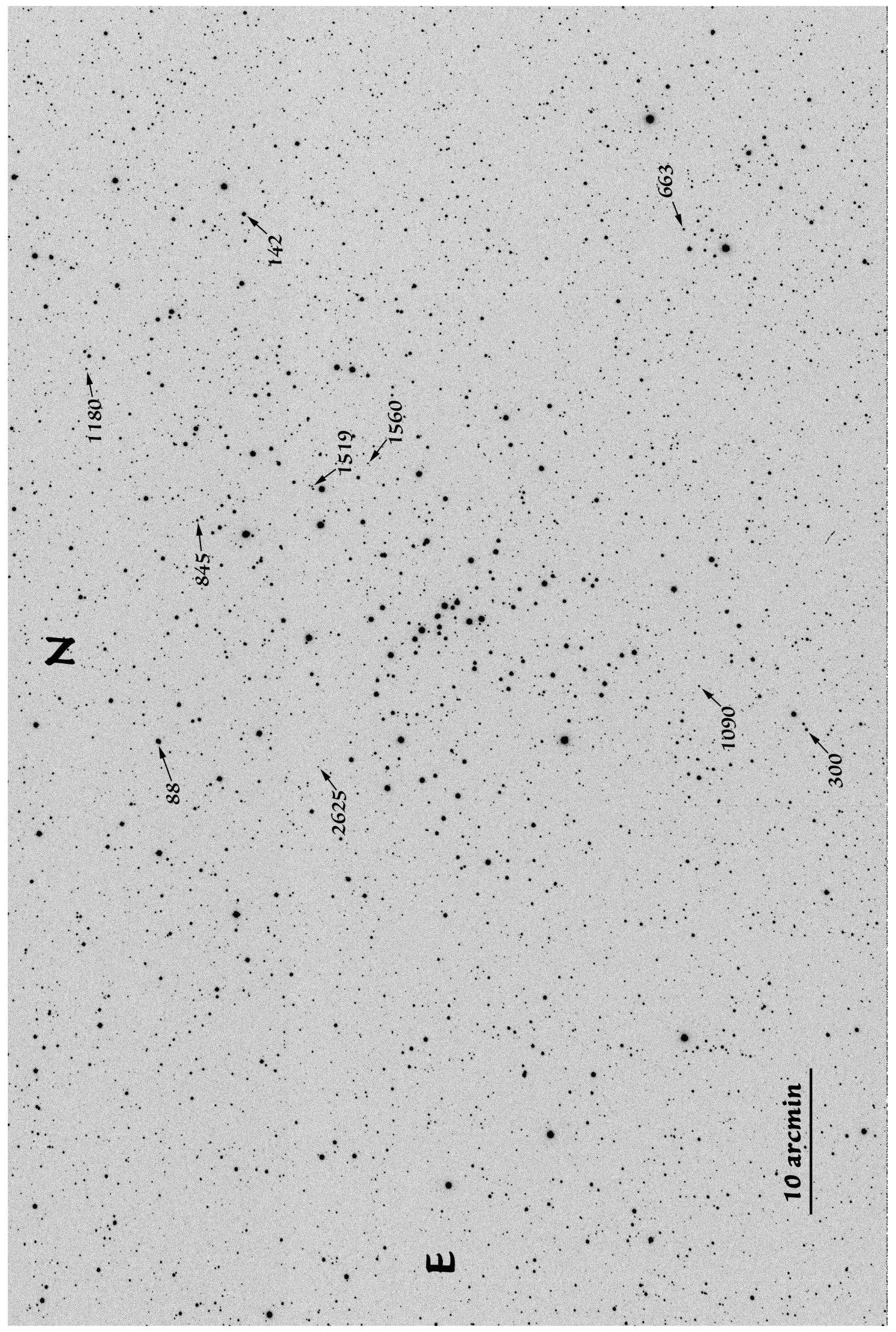

그림 1. M48 영역에서 관측된 변광성의 분포도. 화살표로 나타낸 변광성에 측광 과정에서 부여한 밝기 순의 별 번호를 나타내었다. 

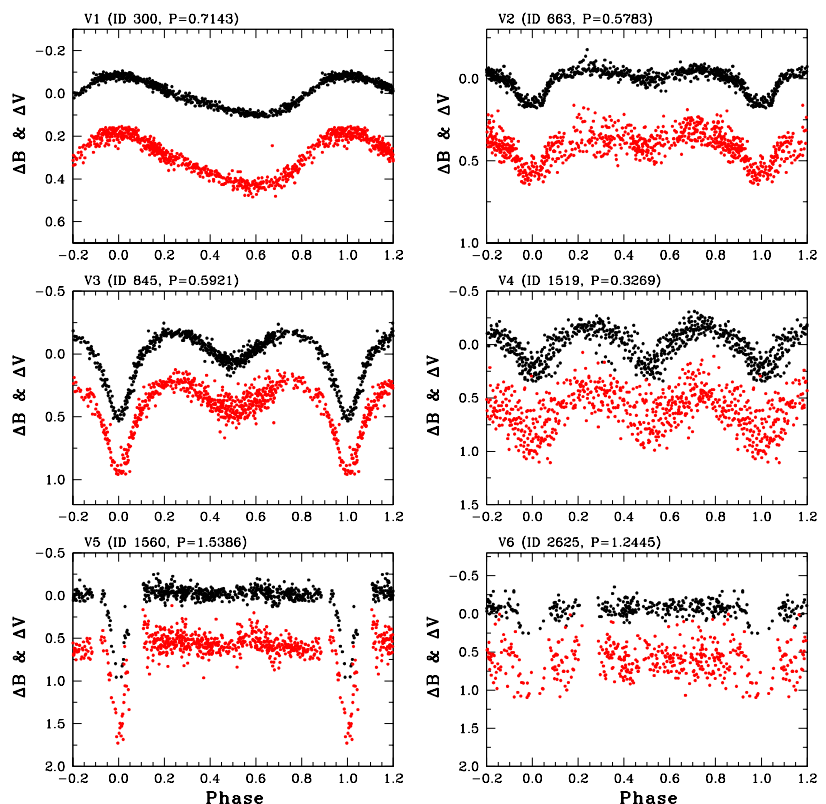

그림 2. RR Lyrae 변광성 하나와 5 개 식쌍성의 위상을 맞 춘 광도곡선.

주기의 변광 여부를 살펴 보았으나 뚜렷한 변광을 보 이는 대상이 없어서 이 연구에서는 이들 자료를 제외 하였다.

관측한 $\mathrm{CCD}$ 영상자료는 $\mathrm{IRAF} / \mathrm{CCDRED}$ (Stetson, 1987; Massey \& Davis, 1992)를 이용하여 영점보정, 암 잡음보정, 플랫보정의 전처리 과정을 수행하였다. 전 처리 과정과 측광 과정은 이전과 같다(Jeon et al., 2005, 2007; Jeon, 2009a, 2009b). M48 영역에서 측광을 수행 한 별은 모두 5,400 여개이며, 이들 모두에 대해 각각의 비교성을 설정하여 차등등급을 구한 후 광도곡선을 컴 퓨터 화면에 하나씩 출력하여 육안으로 변광 여부를 확 인하였다. 각각의 변광성은 각 변광성에 가급적 가까 이 위치한 별 중에서 밝고 밝기 변화가 없는 별을 비 교성으로 선택하여 차등측광을 수행하였으며, 가장 멀 리 떨어진 비교성의 거리는 약 200 화소인데 약 5.9 분 각이다. 각각의 비교성에 대한 밝기 변화는 별도로 세 밀하게 조사하였다. 이러한 방법은 이전의 연구와 동 일한 방법이다(Jeon, 2009a, 2009b, 2010a; Jeon \& Lee, 2010b).

그림 1 은 $V$ 필터로 관측된 $\mathrm{M} 48$ 영역의 영상이며, 이 연구에서 새로 찾은 변광성을 화살표로 나타내었 다. 별의 번호는 측광 과정에서 부여한 것으로 밝기 순 이다.

\section{3. 결과}

표 1 에 각 변광성에 관련된 정보를 수록하였다. 별의 $\mathrm{ID}$ 는 측광 과정에서 부여한 것인데 $V$ 등급의 밝기 순 이다. 좌표는 $\mathrm{SIMBAD}^{2}$ 에서 구하였으며, $V$ 등급과 $(B-V)$ 색지수는 $\operatorname{Pesch}(1961)$ 의 광전 측광 자료에서

\footnotetext{
${ }^{2}$ http://simbad.u-strasbg.fr/simbad/
}
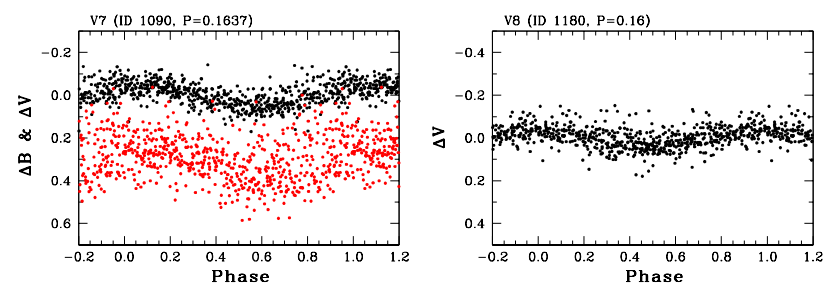

그림 3. $\delta$ Scuti 형 변광성의 위상을 맞춘 광도곡선.

영점 보정하여 얻은 것이다. 먼저 비교성에 대한 영점 보정치를 얻고, 변광성의 광도곡선을 얻은 전체 관측 치에 대한 평균값을 구한 후 영점 보정한 비교성의 등 급에 더하여 평균 등급을 얻었다. 주기는 위상 맞추기 방법으로 구하였으며, 변광진폭은 위상을 맞춘 광도곡 선에서 분산 값을 고려한 최대치와 최소치를 읽어서 얻 은 값이다. Wu et al.(2002)의 고유운동 연구 결과로부 터 변광성의 성단별 여부를 확인하였는데 10 개 중 3 개 에 대해서 확인할 수 있었다. 그 중에서 V1과 V9는 성 단별일 가능성이 없으며, $\mathrm{V} 10$ 은 성단별일 가능성이 높 다. 하지만 $\mathrm{V} 10$ 의 경우 큰 색지수 값을 가지는 적색 거 성으로 보이나 주계열 전향점보다 2 등급 이상 어두워 서 성단별일 가능성이 낮다.

표 1 의 마지막 칸에 변광성의 종류를 분류하여 기록 하였다. $\mathrm{GCVS}^{3}$ (Samus et al., 2004)에서 이 연구에서 관측한 M48 영역 내에는 알려진 변광성이 전혀 없다. 또한 $\mathrm{ASAS}^{4}$ (Pojmanski, 2002) 에서도 오직 하나의 변 광성 후보만 수록되었을 뿐인데 이 연구에서는 밝기 변 화를 확인하지 못하였다. 따라서 표 1 의 변광성은 모 두 새로 발견한 것이다.

그림 2는 RR Lyrae 형 변광성 하나(V1)와 식쌍성 5 개 $(\mathrm{V} 2-\mathrm{V} 6)$ 의 위상을 맞춘 광도곡선이다. 표 1 에서 $\mathrm{V} 1$ 은 $\mathrm{M} 48$ 의 성단별이 아니며 변광진폭 $\Delta B$ 와 $\Delta V$ 가 각각 0.27 과 0.19 이다. 주기는 0.7143 일이며, 비 대칭적 인 광도곡선의 형태로 보아 RRab형으로 볼 수 있다.

$\mathrm{V} 2$ 와 $\mathrm{V} 3$ 는 $\mathrm{EB}$ 형 식쌍성의 광도곡선을 보이는데 주 기가 각각 0.5783 일과 0.5921 일이다. $\mathrm{V} 4$ 는 $\mathrm{EW}$ 형의 식 쌍성이며 서로 비슷한 $\Delta B$ 와 $\Delta V$ 의 변광진폭비로부터 맥동변광성일 가능성은 없다. V5와 $\mathrm{V} 6$ 는 $\mathrm{EA}$ 형 식쌍 성의 광도곡선을 보인다. 이들의 주기는 각각 0.1637 일 과 0.16 일로 비슷하다. 두 별 모두 어두워서 정밀한 광 도곡선을 얻지 못하였고, 부극소가 뚜렷하게 드러나지 않는다. 특히 $\mathrm{V} 6$ 의 $B$ 등급 광도곡선은 분산이 커서 주 극소가 형태만을 겨우 보여주고 있다. 표 1에서 식쌍성 $\mathrm{V} 2-\mathrm{V} 6$ 의 $\Delta B$ 와 $\Delta V$ 의 변광진폭 값이 서로 비슷한 값 을 보이고 있다. 반면에 맥동 변광성인 $\mathrm{V} 1$ 의 경우 두 진폭간의 비가 약 0.7 로써 $\Delta B$ 가 크게 나타난다. Jin et al.(2004)에 따르면 $\Delta B$ 와 $\Delta V$ 의 변광진폭비로부터 식 쌍성과 맥동변광성을 구분할 수 있는데 그림 2 의 변광 성은 이러한 특징을 잘 보여주고 있다.

\footnotetext{
3 http://www.sai.msu.su/gcvs/gcvs/

4 http://www.astrouw.edu.pl/asas/
} 
표 1. M48 영역에서 새로 발견한 변광성의 좌표와 물리량

\begin{tabular}{|c|c|c|c|c|c|c|c|c|c|c|c|c|c|c|}
\hline \multirow{2}{*}{ Name } & \multirow[t]{2}{*}{ ID } & \multirow{2}{*}{\multicolumn{3}{|c|}{$\begin{array}{c}\text { RA } \\
(\mathrm{J} 2000.0) \\
\end{array}$}} & \multirow{2}{*}{\multicolumn{3}{|c|}{$\begin{array}{c}\text { DEC } \\
(\mathrm{J} 2000.0) \\
\end{array}$}} & \multirow{2}{*}{$\begin{array}{l}<V> \\
(\mathrm{mag}) \\
\end{array}$} & \multirow{2}{*}{$\begin{array}{c}<B>-<V> \\
(\mathrm{mag})\end{array}$} & \multirow{2}{*}{$\begin{array}{l}\text { Period } \\
\text { (day) }\end{array}$} & \multicolumn{2}{|c|}{ Amplitude } & \multirow{2}{*}{$\begin{array}{l}{ }^{a} \text { Membership } \\
\text { probability }\end{array}$} & \multirow[t]{2}{*}{${ }^{b}$ Type } \\
\hline & & & & & & & & & & & $\Delta B(\mathrm{mag})$ & $\Delta V(\mathrm{mag})$ & & \\
\hline V1 & 300 & 8 & 14 & 16.313 & -6 & 9 & 56.76 & 12.48 & 0.45 & 0.7143 & 0.27 & 0.19 & 0.00 & RRab \\
\hline $\mathrm{V} 2$ & 663 & 8 & 12 & 3.017 & -6 & 2 & 56.17 & 13.61 & 0.55 & 0.5783 & 0.25 & 0.23 & - & $\mathrm{EB}$ \\
\hline V3 & 845 & 8 & 13 & 15.740 & -5 & 30 & 21.00 & 14.09 & 0.36 & 0.5921 & 0.73 & 0.72 & - & $\mathrm{EB}$ \\
\hline $\mathrm{V} 4$ & 1519 & 8 & 13 & 7.749 & -5 & 37 & 58.22 & 14.90 & 0.57 & 0.3269 & 0.43 & 0.42 & - & EW \\
\hline V5 & 1560 & 8 & 13 & 2.148 & -5 & 41 & 41.15 & 14.96 & 0.27 & 1.5386 & 1.1 & 1.0 & - & EA \\
\hline V6 & 2625 & 8 & 14 & 21.851 & -5 & 37 & 46.20 & 15.85 & 0.51 & 1.2445 & $(1.1)^{c}$ & 1.1 & - & EA \\
\hline V7 & 1090 & 8 & 14 & 3.855 & -6 & 2 & 58.82 & 14.37 & 0.74 & 0.1637 & 0.20 & 0.14 & - & DSCT \\
\hline V8 & 1180 & 8 & 12 & 34.791 & -5 & 23 & 22.87 & 14.47 & 0.74 & 0.16 & 0.15 & $(0.1)^{c}$ & - & DSCT \\
\hline V9 & 88 & 8 & 14 & 13.641 & -5 & 27 & 16.07 & 10.65 & 0.73 & - & - & - & 0.00 & $\mathrm{~L}$ \\
\hline V10 & 142 & 8 & 11 & 55.225 & -5 & 34 & 3.67 & 11.06 & 1.61 & - & - & - & 0.87 & $\mathrm{~L}$ \\
\hline
\end{tabular}

${ }^{a}$ Wu et al. (2002).

${ }^{b}$ 변광성 형태의 표기는 GCVS의 분류법에 따름.

$c$ 오차가 큼.
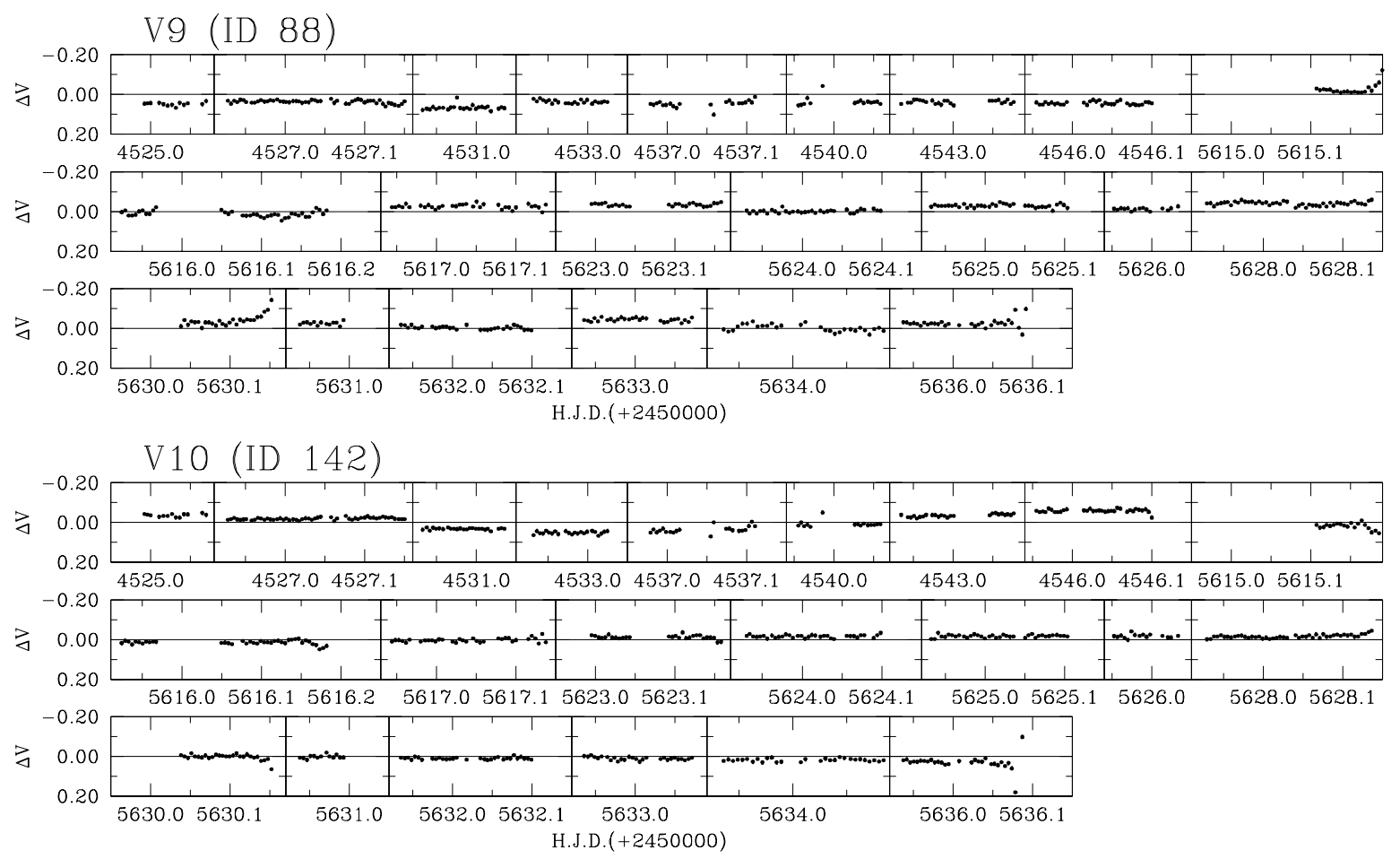

그림 4. 주기를 구할 수 없는 V9와 V10의 두 변광성의 광도곡선. 
그림 3 에서 $\mathrm{V} 7$ 과 $\mathrm{V} 8$ 은 표 1 의 주기와 $\Delta B$ 와 $\Delta V$ 의 변광진폭비는 맥동변광성임을 시사하고, 짧은 변광주 기로 볼 때 $\delta$ Scuti형 변광성일 가능성이 높다. $\mathrm{V} 8$ 은 $B$ 등급 광도곡선의 분산이 너무 커서 그림에서 제외했 다. 각 별의 밝기로 미루어 보아 성단별일 가능성은 없 다.

그림 4 에 주기를 구할 수 없는 두 변광성의 광도곡 선을 나타내었다. 이들은 주기가 길거나, 비주기성이 어서 현재의 자료만으로 주기와 진폭을 얻기 어렵다. 따라서 오랜 기간에 걸쳐서 느리게 변광하는 형태로서 GCVS 분류법에 따라 L형으로 분류하였다.

그림 5 는 각 변광성의 색-등급도 상의 위치를 나타 낸 것이다. $B$ 와 $V$ 등급은 $\operatorname{Pesch}(1961)$ 에 의해 광전 측 광이 이루어진 8 개의 별을 택하여 영점을 보정하였다. Pesch(1961)의 광전측광 별은 대부분 너무 밝아서 영 점 보정에 사용할 수 있는 별의 수가 적어서 색지수 보정 까지는 하지 못하였다. 관측 영상 중에서 시상이 좋은 $B$ 와 $V$ 각각 하나씩을 선택하여 그림 5 의 색-등급도를 얻었다. 영점 보정치는 $B$ 등급에 대해 $1.63 \pm 0.03, V$ 등급에 대해 $0.96 \pm 0.01$ 이다 하지만 변광성의 등급과 색지수는 광도곡선을 얻는데 사용한 전체 자료를 평균 하여 얻은 값이다.

\section{4. 요약 및 검토}

산개성단 M48(NGC 2548) 영역에 대해 총 22 일의 관 측 자료를 이용하여 변광성 탐사를 수행한 결과 모두 10 개의 새로운 변광성을 발견하였다. 이들은 식쌍성 5 개, $\delta$ Scuti형 2개, RR Lyrae형 1개, 그리고 느리게 변 광하는 L형 2 개였다. GCVS와 $\mathrm{ASAS}$ 에서 이 연구의 관 측 영역 내에는 알려진 변광성이 하나 뿐이었는데 이 연구에서 변광 여부를 확인하지 못했다. 따라서 이 연 구에서 얻은 10 개 모두 새로운 변광성으로 볼 수 있다. $\mathrm{Wu}$ et al.(2002)의 고유운동 연구로부터 이들 중 $\mathrm{L}$ 형 1 개(V10)는 성단별일 가능성이 높고, V1과 V9는 성단 별이 아닌 것으로 알려졌다. 하지만 $\mathrm{V} 10$ 은 주계열 전 향점보다 2 등급 이상 어두워서 성단별이 아닐 가능성 이 높다. 성단별 여부가 알려지지 않은 7 개의 변광성 중에서 2 개의 $\delta$ Scuti형 변광성 $(\mathrm{V} 7, \mathrm{~V} 8)$ 은 밝기를 고려 하면 성단별일 가능성이 없고, 나머지는 성단별 여부 를 확인하기 어렵다.

\section{감사의 글}

This research has made use of the SIMBAD database, operated at CDS, Strasbourg, France.

\section{참고 문헌}

Balaguer-Núñez, L., Jordi, C., \& Galadí-Enríquez, D., 2005, uvby $\mathrm{H} \beta$ CCD Photometry and Membership Segregation of the Open Cluster NGC 2548;

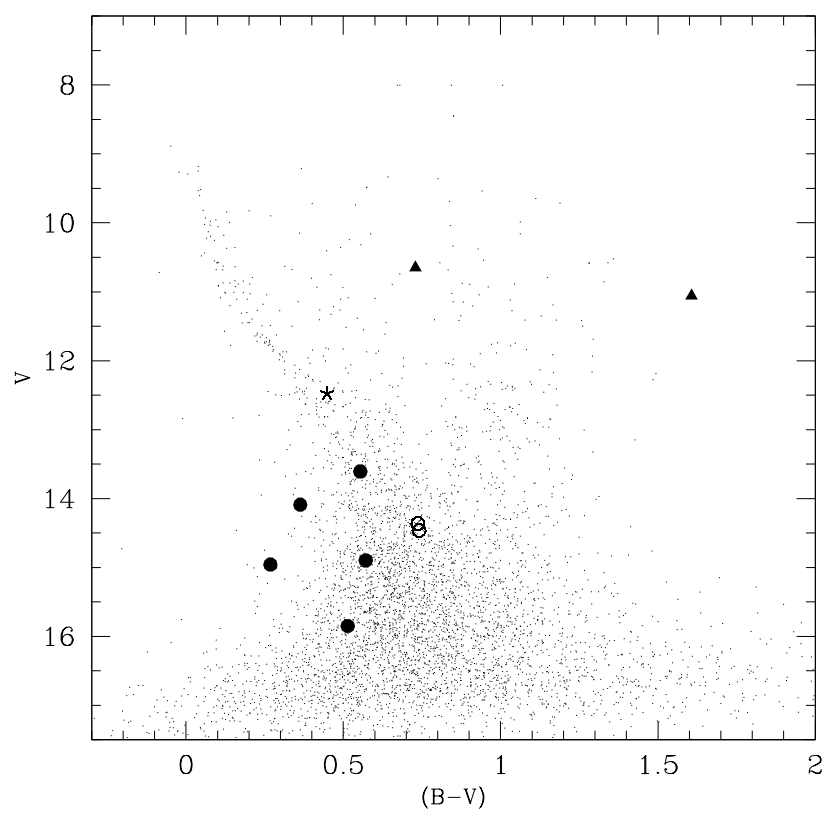

그림 5. 변광성을 포함한 M48 영역의 색-등급도. 검은 원 은 식쌍성, 흰원은 $\delta \mathrm{Scuti}$ 형, 별모양은 RR Lyrae 형, 검은 삼각형은 $\mathrm{L}$ 형 변광성이다.

Gaps in the Main Sequence of Open Clusters, A\&A, 437, 457

Ebbighausen, E. G., 1939, Proper Motions in the Galactic Cluster NGC 2548, ApJ, 90, 689

Jeon, Y. -B., 2008, Variable Stars in the Region of an Open Cluster M50, PKAS, 23, 17

Jeon, Y. -B., 2009a, New Variable Stars in the Region of the Open Cluster M38 (NGC 1912) I: $\delta$ Scuti and $\gamma$ Doradus Type Stars, PKAS, 24, 9

Jeon, Y. -B., 2009b, Variable Stars in the Region of an Young Open Cluster M29 (NGC 6913), PKAS, 24,19

Jeon, Y. -B., 2010a, New Variable Stars in the Region of the Open Cluster M38 (NGC 1912) II, PKAS, 25,1

Jeon, Y. -B., Kim, S. -L., Park, Y. -H., et al., 2005, Short-Period Variability Survey (SPVS) in BOAO, PKAS, 20, 21

Jeon, Y. -B. \& Lee, H. -R., 2010b, New Variable Stars in the Region of the Open Cluster M35 (NGC 2168), PKAS, 25, 167

Jeon, Y. -B., Nam, K. -H., Park, Y. -H., et al., 2007, Preliminary Results for Short-Period Variability Survey (SPVS): New Field Variable Stars, PKAS, 22,141

Jin, H., Kim, S. -L., Lee, C. -U., et al., 2004, Reclassification of ROTSE-I $\delta$ Scuti Stars with Multiband Photometry and Fourier Decomposition, AJ, 128, 1847

Massey, P. \& Davis, L. E., 1992, A User's Guide to Stellar CCD Photometry with IRAF 
Pesch, P., 1961, Photometric and Objective Prism Observations in Three Galactic Clusters, ApJ, 134, 602

Pojmanski, G., 2002, The All Sky Automated Survey. Catalog of Variable Stars. I. 0h - 6h Quarter of the Southern Hemisphere, AcA, 52, 397

Rider, C. J., Tucker, D. L., Smith, J. A., Stoughton, C., et al., 2004, A Survey of Open Clusters in the $u^{\prime} g^{\prime} r^{\prime} i^{\prime} z^{\prime}$ Filter System. I. Results for NGC 2548 (M48), AJ, 127, 2210

Samus, N. N., Durlevich, O. V., et al., 2004, Combined General Catalogue of Variable Stars (Samus+2004), VizieR Online Data Catalog, 2250

Sharma, S., Pandey, A. K., Ogura, K., Mito, H., et al., 2006, Wide-Field CCD Photometry Around Nine Open Clusters, AJ, 132, 1669

Stetson, P. B., 1987, DAOPHOT - A Computer Program for Crowded-Field Stellar Photometry, PASP, 99, 191

Wu, Z. Y., Tian, K. P., Balaguer-Núñez, L., et al., 2002, Determination of Proper Motions and Membership of the Open Star Cluster NGC 2548, A\&A, 381, 464

Wu, Z. -Y., Zhou, X., Ma, J., Jiang, Z. -J., \& Chen, J. -S., 2006, Membership Determination of Open Cluster M48 Based on BATC 13-Band Photometry, PASP, 118, 1104 